\title{
Sífilis y embarazo: una enfermedad re-emergente
}

\section{Reporte de un caso}

Caldera-Mejía Karla Michelle*, Briseño-Campos Antonio Gabriel*, Robles-Martínez

María del Consuelo**

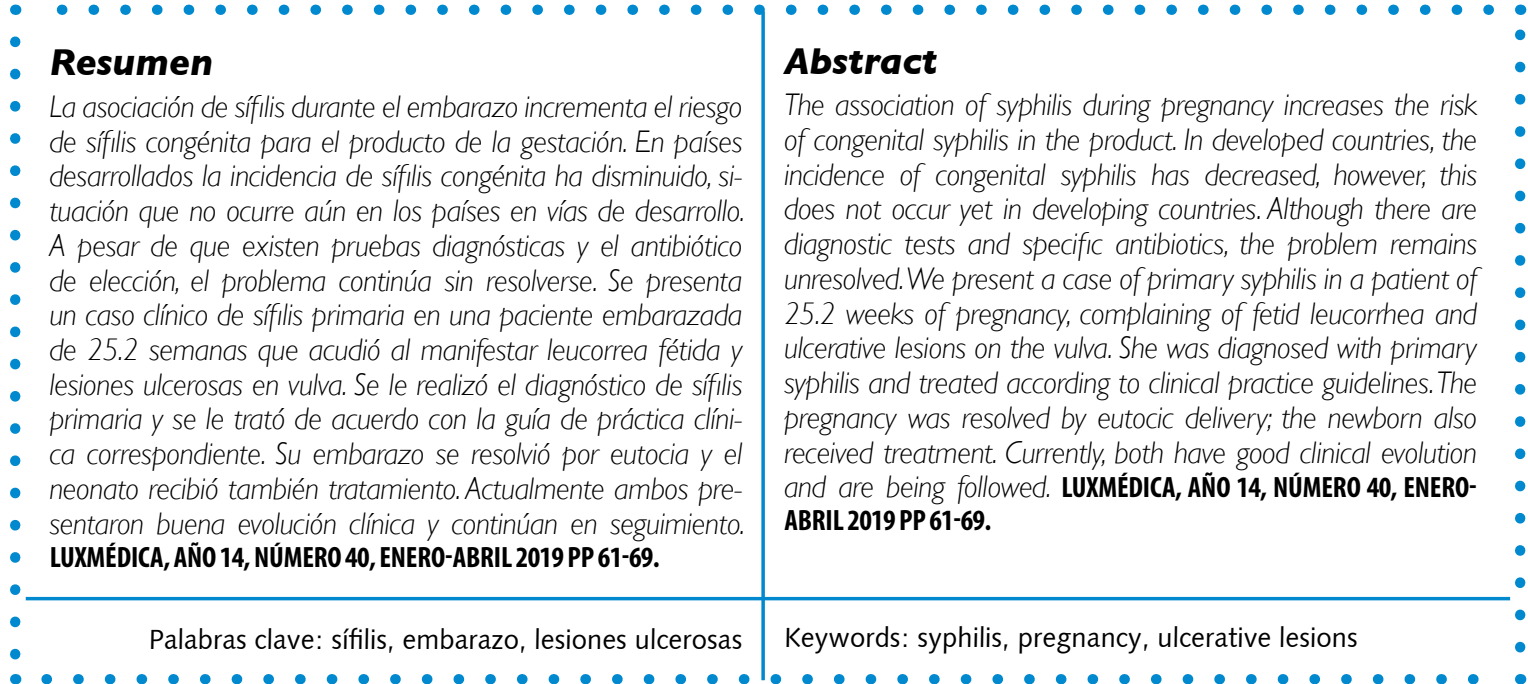

\section{Introducción}

La sífilis es una enfermedad que pertenece al grupo de padecimientos que se adquiere y trasmite por actividad sexual. Se han denominado también "infecciones de transmisión sexual" bajo el argumento de que abarcan ambas, la presentación sintomática y asintomática. ${ }^{1}$ Es una enfermedad cuyo agente etiológico es el Treponema pallidum, una bacteria perteneciente a la familia de las espiroquetas. El contagio se produce por contacto directo con una lesión mucocutánea infectada. ${ }^{2,3}$

Las mujeres gestantes infectadas por sífilis pueden transmitir la infección al feto, provocándole sífilis congénita (SC), lo que puede

* Médicos residentes del cuarto año de la especialidad de Ginecología y Obstetricia del Hospital de la Mujer de Aguascalientes. México Profesora Titular del Posgrado de Ginecología y Obstetricia del Hospital de la Mujer de Aguascalientes. México

Fecha de recibido: 2 de abril 2018

Fecha de aceptación: 17 de septiembre 2018

Correspondencia: Dra María del Consuelo Robles Martínez. Hospital de la Mujer. Avenida Siglo XXI Número 109. Ciudad Satélite Morelos. Código postal 20270. Aguascalientes, Aguascalientes, México. Teléfono (01) 4499773330 y 32. Correo electrónico dracheroblesm@gmail.com 
asociarse a eventos adversos graves para el embarazo. No obstante, existen opciones para su detección y tratamiento que son sencillas, relativamente baratas y muy efectivas que contribuirían positivamente en los esfuerzos para la eliminación de la SC. ${ }^{4}$

En la mayoría de las ocasiones el diagnóstico se hace a través de los resultados de las pruebas de tamizaje que se solicitan en el control prenatal o en el parto. Se considera sífilis gestacional a toda mujer gestante, puérpera o con aborto reciente, que tenga al menos una prueba no treponémica (VDRL o RPR) positiva con títulos iguales o mayores a 1:8 diluciones, o en menos diluciones (1:2 o 1:4) siempre y cuando tenga una prueba treponémica (FTA-abs o TPH) positiva. ${ }^{3,5}$ Mientras que se considera caso compatible de sífilis congénita a todo producto de la gestación (aborto, mortinato o nacido vivo) de madre con sífilis gestacional sin tratamiento o tratamiento inadecuado, independientemente de que el producto presente o no signos de enfermedad y del resultado de las pruebas no treponémicas. ${ }^{6}$

La sífilis congénita se debe al paso transplacentario del Treponema pallidum, aunque también puede producirse la infección fetal por contacto directo con una lesión a través del canal de parto. La transmisión durante el periodo de lactancia materna es infrecuente, salvo aquellos casos en que existen lesiones infecciosas en la mama. ${ }^{2}$ En el caso de la sífilis congénita, la tasa más alta de infección se debe a la transmisión vertical, existiendo un menor porcentaje de casos debidos a la infección en el canal del parto y en relación con la lactancia materna. El riesgo de infección fetal por enfermedad materna reciente no tratada es del 80-90\%. En el pasado estaba establecida la idea de que la infección fetal no ocurría antes de la semana 18 de gestación, debido al efecto protector que ejercía la capa de células de Langhans de la placenta. Sin embargo, nuevas técnicas de diagnóstico, como PCR en líquido amniótico o en tejidos fetales, han demostrado el paso transplacentario del T. pallidum en la semana 9-10 de gestación. ${ }^{3,5}$

En la historia natural de la enfermedad se distinguen diferentes etapas: periodo de incubación, sífilis primaria, sífilis secundaria (precoz y tardía), periodo de latencia y sífilis terciaria. ${ }^{1}$ No existen evidencias que demuestren que el embarazo afecta al curso clínico de esta enfermedad. ${ }^{7}$ El diagnóstico se sospecha por los datos clínicos característicos de la misma y la confirmación diagnóstica se establece por medio de pruebas serológicas. ${ }^{8}$ El tratamiento antibiótico de elección es la penicilina, también durante la gestación, $y$, aunque existen fármacos alternativos, ninguno ha conseguido tasas de efectividad comparables a ésta. ${ }^{7}$

Es necesario y urgente de recopilar datos estadísticos confiables de prevalencia de las infecciones de transmisión sexual en los países de ingresos medios, donde la carga entre las mujeres embarazadas es mayor. ${ }^{9}$ La detección de sífilis en el embarazo (realizando el tamizaje oportuno en el control prenatal), comprueba que las 
intervenciones básicas son costo-beneficio efectivas incluso en lugares con baja prevalencia. ${ }^{7}$ Está comprobado que el tamizaje para la búsqueda de sífilis en mujeres embarazadas está asociado con la disminución de la incidencia de sífilis congénita. ${ }^{10-12}$ En México, la NOM 039 y 007 contemplan el protocolo de atención de la paciente embarazada y su producto de gestación. ${ }^{13,14}$

\section{Presentación del caso clínico}

Se presenta paciente adolescente de 15 años, que cursa su primer embarazo, refiere haber acudido en dos ocasiones a consulta a un centro de salud. Es vista en el servicio de urgencias de ginecología y obstetricia del Hospital de la Mujer de Aguascalientes por presentar flujo transvaginal abundante, refractaria a tratamiento farmacológico. Al interrogarla sobre antecedentes de importancia, se recaba que inició vida sexual activa a los 14 años, y ha tenido dos parejas sexuales. Última pareja de 22 años. No ha utilizado ningún método de planificación familiar. Por ultrasonido se confirma embarazo de 25.2 semanas. A la exploración física encontramos cabeza, cuello y tórax, sin datos que consignar. Abdomen globoso a expensas de útero gestante, depresible, no doloroso a la palpación superficial ni profunda con producto único vivo intrauterino, en situación longitudinal, fondo uterino de $25 \mathrm{~cm}$, y presentación cefálica, con dorso a la derecha y una frecuencia cardiaca fetal de 140 latidos por minuto. No se percibe actividad uterina. A la exploración genital se observa edema de labios menores con varias lesiones ulceradas de aproximadamente $1.5 \mathrm{~cm}$ de diámetro, en labios menores y mayores, con secreción blanquecina y verdosa, con bordes indurados y eritematosos (figura 1). Al tacto vaginal se encontró cérvix posterior cerrado largo, leucorrea verdosa fétida espumosa. Se palpan entre 4 y 5 adenomegalias inguinales bilaterales de consistencia semiblanda, de aproximadamente medio centímetro de diámetro, dolorosas discretamente. Resto de exploración sin datos que comentar.

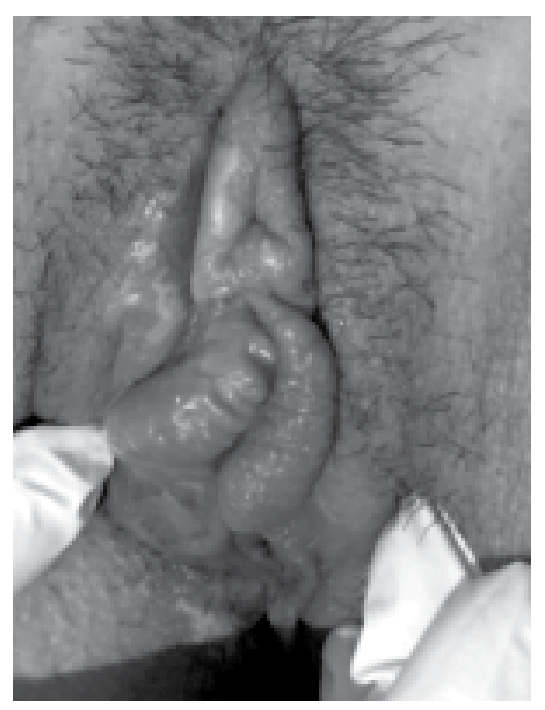

Figura 1. Úlceras en genitales externos. Nótese en labio menor derecho hacia el introito la lesión sifilítica; a la palpación es una lesión indurada. En surcos interlabiales y región perineal, se presentaban varias úlceras con secreción purulenta. 
En urgencias se realiza prueba VDRL rápida, con resultado positivo. Se informa al Servicio de Epidemiología. Se toman muestras de sangre para realizar prueba confirmatoria (tabla 1), y se toma prueba de VIH la cual resulta negativa. Se indica tratamiento con penicilina benzatínica a dosis de 2.4 millones de unidades semanales por 3 dosis; se aplica primera dosis el 28 de diciembre del 2017, pero la paciente no acude a sus citas subsecuentes. Es captada nuevamente para reiniciar tratamiento el 12 de enero del 2018.

\begin{tabular}{|c|c|}
\hline Prueba de laboratorio de ingreso & Resultados \\
\hline Grupo sanguíneo y Rh & A positivo \\
\hline Leucocitos & 10,200 \\
\hline Neutrófilos & 7,910 \\
\hline Linfocitos & 1,310 \\
\hline Hemoglobina & $11.4 \mathrm{gr} / \mathrm{dl}$ \\
\hline Hematocrito & $33.1 \%$ \\
\hline Plaquetas & 344000 \\
\hline VDRL & Positivo 1:128 \\
\hline TPHA & Positivo \\
\hline RPR & Positivo 1:64 \\
\hline $\mathrm{VIH}$ & Negativo \\
\hline
\end{tabular}

Evolución. Para el 6 de marzo, el VDRL se encontraba positivo 1:8. El 15 de marzo de 2018, la paciente acude a urgencias con 36 semanas de gestación (edad gestacional calculada por biometría fetal) complicado con ruptura precoz de membranas de 24 horas de evolución y trabajo de parto en fase latente, motivo por el cual se inicia conducción. El trabajo de parto concluye en parto eutócico obteniéndose producto único vivo, femenino, asintomática, asignológico, con peso de 2175 gr, Capurro de 35 semanas, Apgar 8/9, líquido amniótico y placenta de características normales. El VDRL de la recién nacida se encontró en 1:4 por lo que se inicia tratamiento con penicilina benzatínica (110.000 UI intramuscular, dosis única). Actualmente ambas permanecen asintomáticas y aún en seguimiento.

\section{| | | | | | | | | | | | | | | | | | | | | | | | | | | | | | | | | | | | | | | | | | | | | | | | | | | | | | | | | | | | | | | | | | | | | | | | | | | | | | | | | | | | | | | | | | | | | | | | || ||}

\section{Discusión}

Las tasas de casos informados de sífilis varían ampliamente de un país a otro, debido, en parte, a la falta de documentación en algunas regiones $y$, por supuesto, a la diferente incidencia de la infección. En la actualidad, la frecuencia de sífilis durante el embarazo ha disminuido considerable- mente, aunque en países subdesarrollados se presenta como enfermedad reemergente. ${ }^{9}$

En México, el Sistema Nacional de Vigilancia Epidemiológica (SINAVE) detecta en el 2010 un repunte anual escalonado de 0.67 casos por cada 100 mil habitantes (figura 1). 


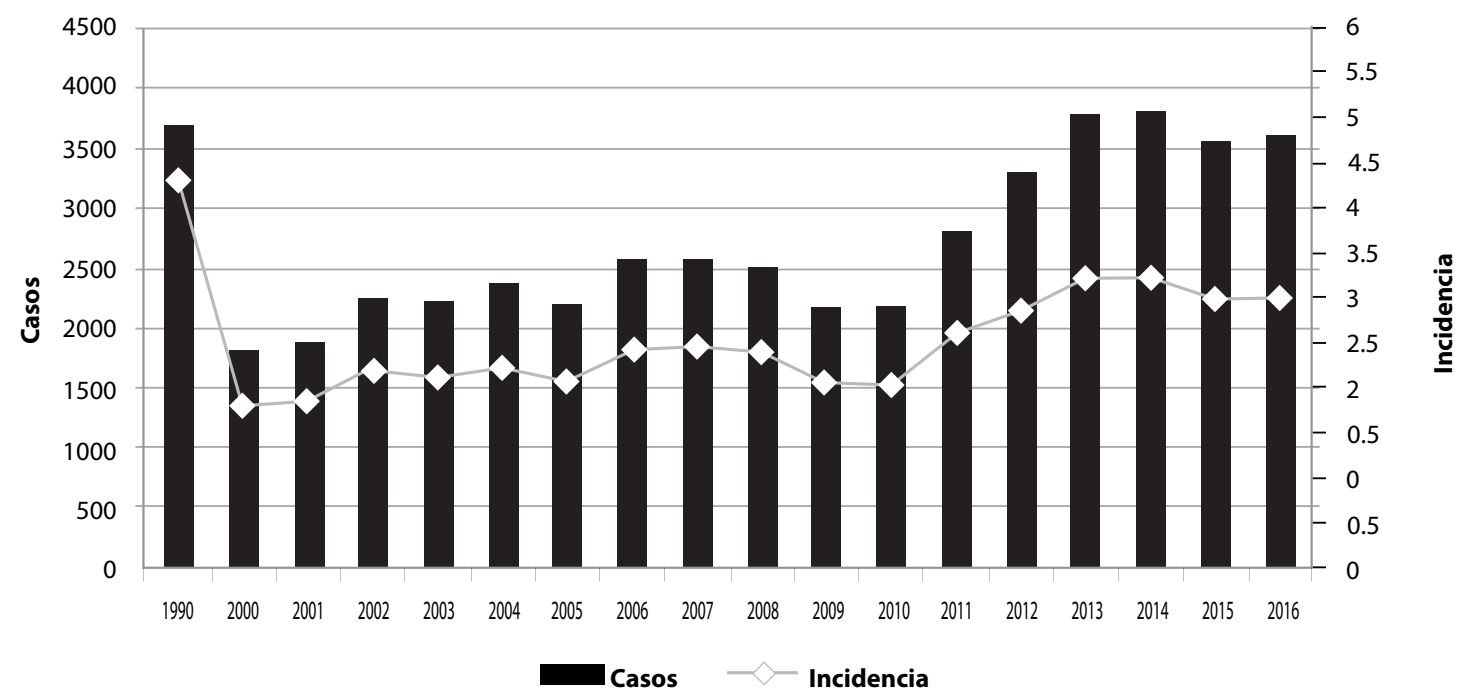

Figura 1. Sífilis adquirida en México. Casos e incidencia de siffilis adquirida en México desde 1990 hasta el 2016; nótese el aumento de la incidencia a partir del 2010. Fuente: Anuario Estadístico 1990 - 2016, DGE/ SSA, disponible en http://www.sinave.gob.mx/

En Aguascalientes el comportamiento de la enfermedad se muestra en la figura 2.

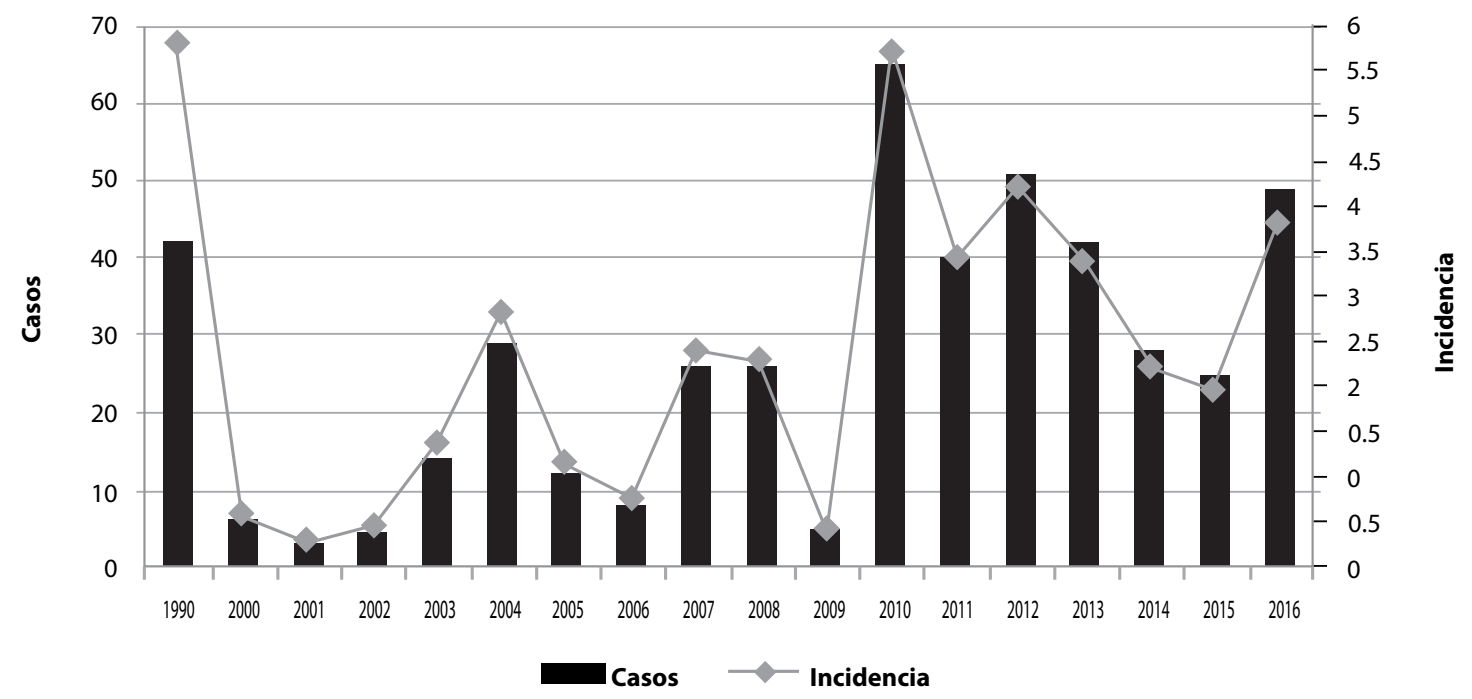

Figura 2. Sifilis adquirida en Aguascalientes. Casos e incidencia de sífilis adquirida en México desde 1990 hasta el 2016; nótese el aumento de la incidencia a partir del 2010. Fuente: Anuario Estadístico 1990 2016, DGE/SSA. Disponible en http://www.sinave.gob.mx/

Con esa información y con la obtenida de los anuarios de Morbilidad de la Secretaria de Salud, se conformaron diversas bases de datos con información diferenciada por sexo, grupo de edad y entidad federativa durante el periodo 2003-2013. Por grupos de edad, en el grupo de 20-25 años, la incidencia de sífilis incrementó de 2.88 casos a 6.77; y en el grupo de 25 a 44 años de 3.12 casos a 7.22 por cada 100 mil personas (Figura 3). 


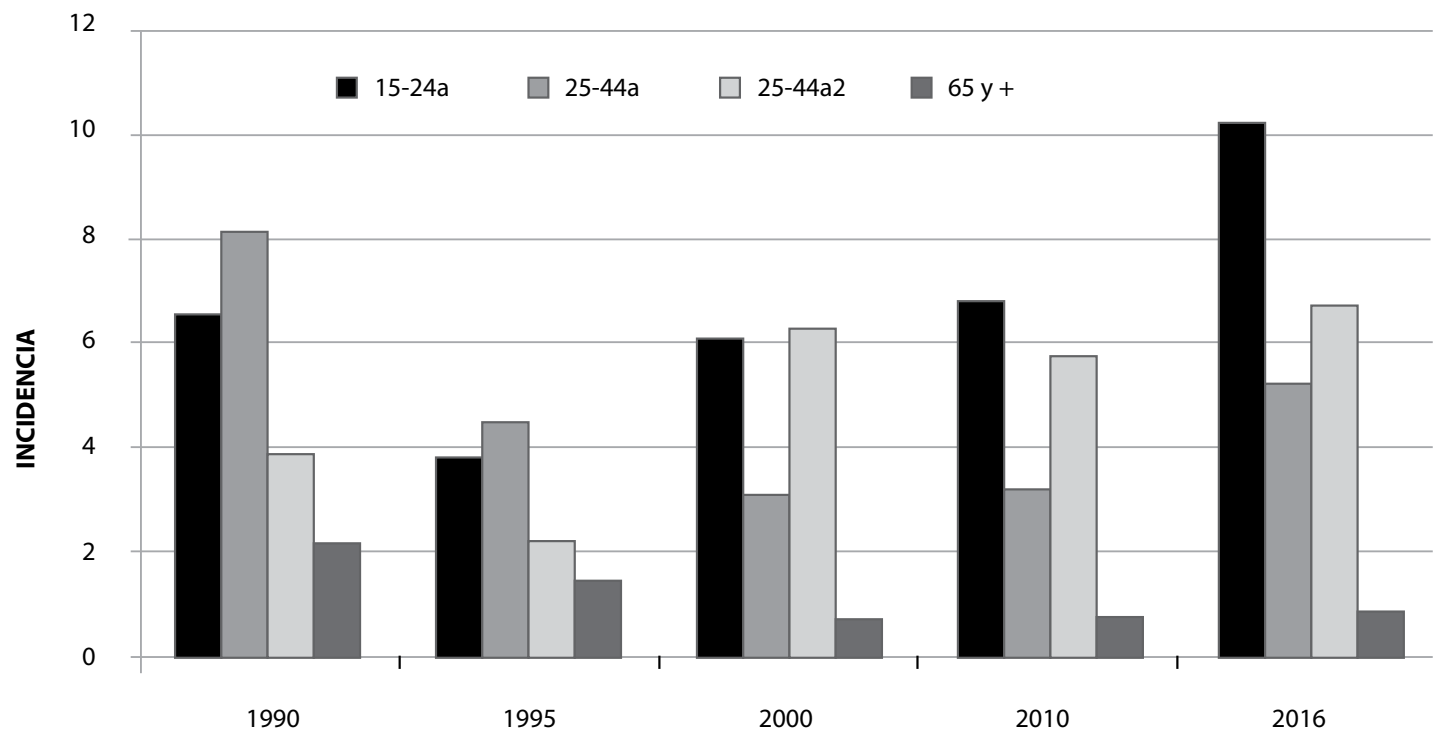

Figura 3. Incidencia de sífilis adquirida según año y edad México, 1990 - 2016. Fuente: Anuario Estadístico 1990 - 2016, DGE/SSA disponible en http://www.sinave.gob.mx/

En Aguascalientes, la incidencia reportada por edad desde 1990 se muestra en la figura 4.

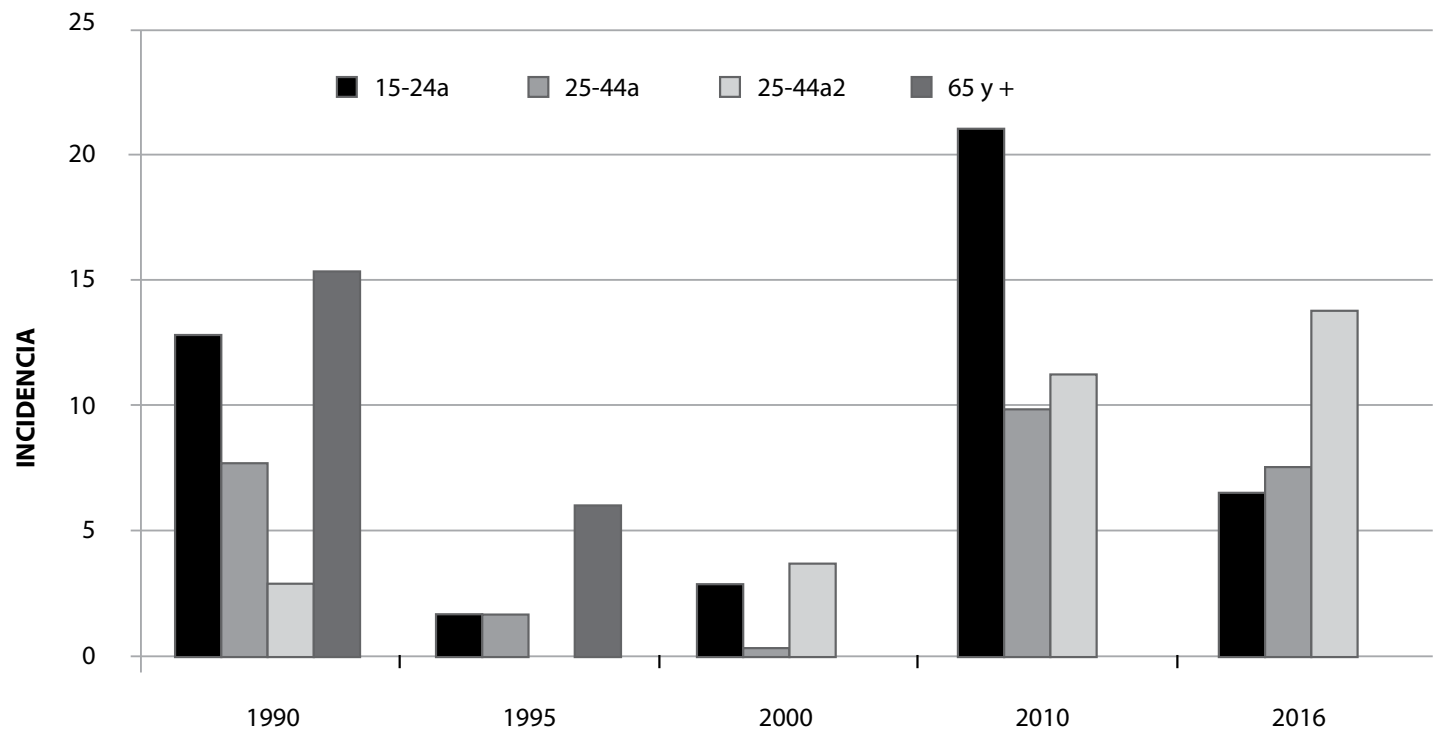

Figura 4. Incidencia de sifilis adquirida según año y edad Aguascalientes, 1990-2016. Fuente: Anuario Estadístico 1990 - 2016, DGE/SSA. Disponible en http://www.sinave.gob.mx/

Las entidades donde se concentra la Sur, Aguascalientes y Puebla. En cuanto a problemática son: Ciudad de México, sífilis congénita las figuras 5 y 6 muestran Quintana Roo, Zacatecas, Baja California la incidencia y número de casos en México. 


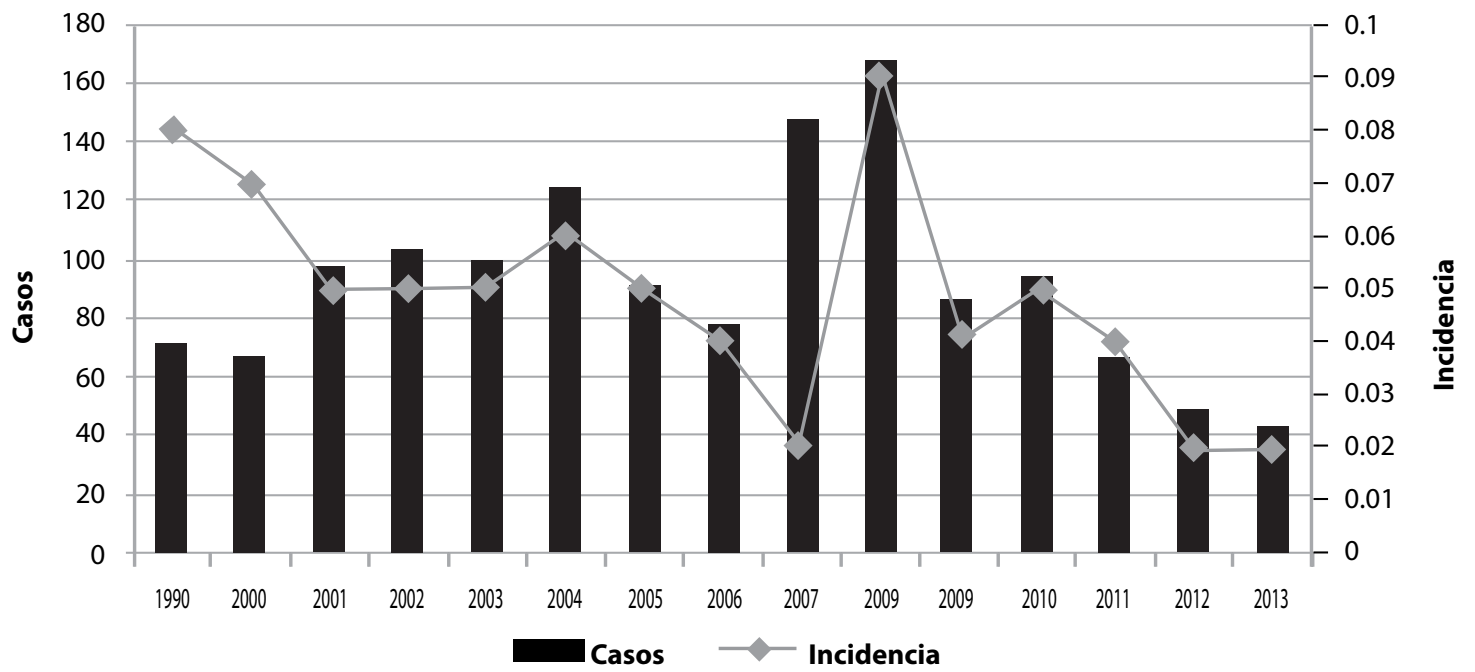

Figura 5. Casos e incidencia de sífilis congénita según año, México, 1990-2013. Fuente: Anuario Estadístico 1990 - 2016, DGE/SSA. Disponible en http://www.sinave.gob.mx/

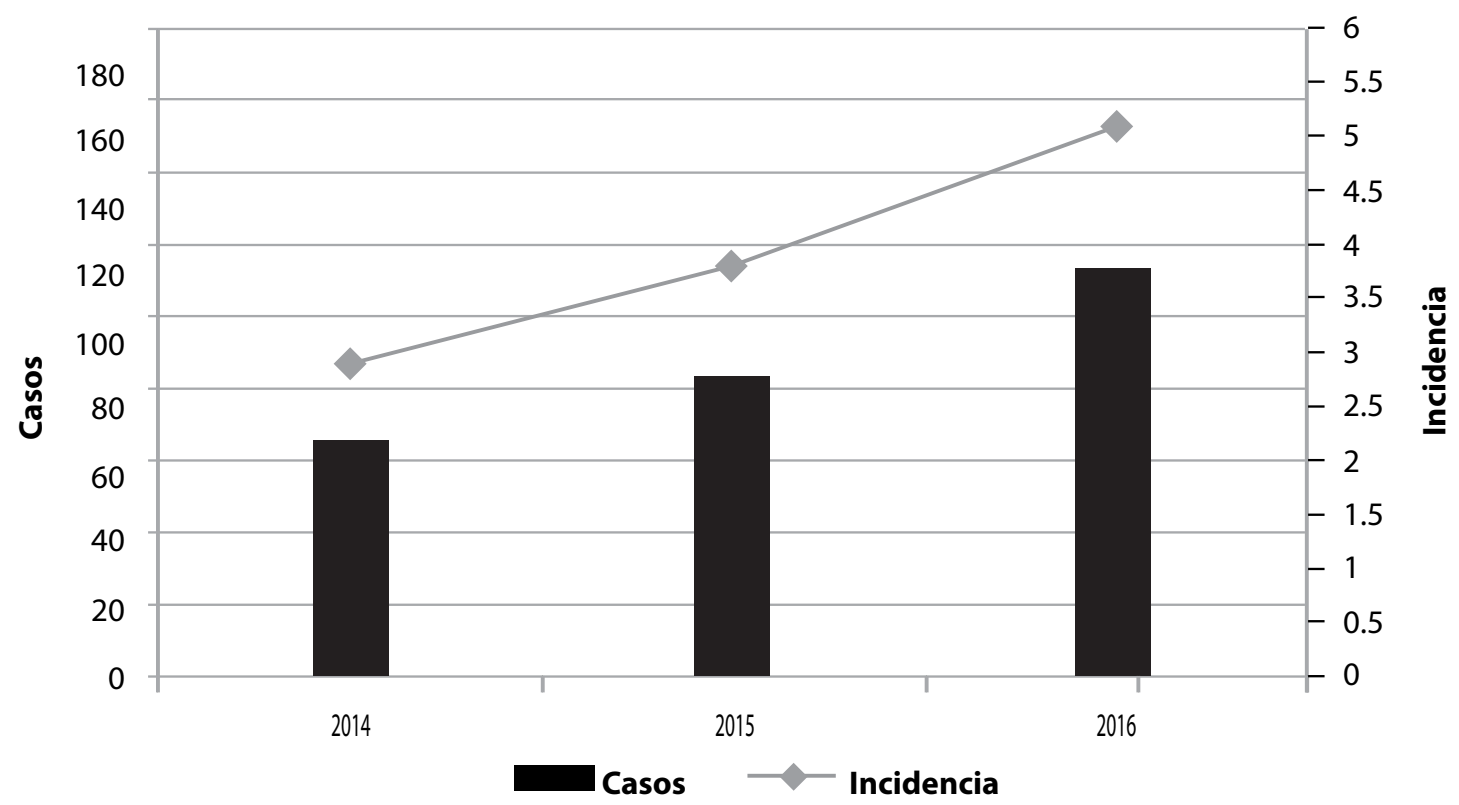

Figura 6. Casos e incidencia de síflis congénita según año, México, 2014-2016. Fuente: Anuario Estadístico 1990-2016, DGE/SSA. Disponible en http://www.sinave.gob.mx/

En Aguascalientes fue notorio el incremento de sífilis congénita en los últimos años (figuras 7 y 8). La enfermedad como sífilis congénita se reporta después de décadas en el 2006 y 2007; posterior al apa- rente control de la enfermedad nuevamente en el 2016 se reportan nuevos casos. Probablemente los reportes sin casos se deba a la falta de tamizajes o al subregistro. 


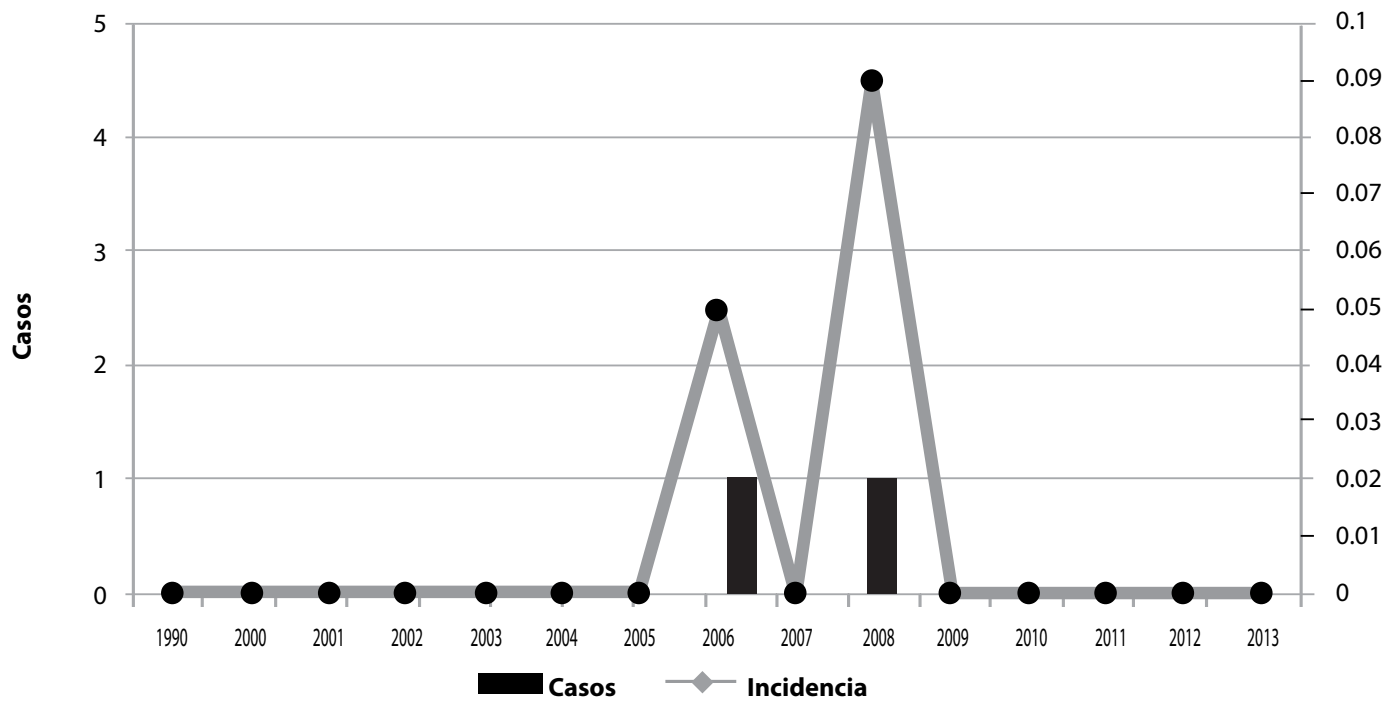

Figura 7. Casos e incidencia de sifilis congénita según año Aguascalientes, 1990 - 2013. Fuente: Anuario Estadístico 1990 - 2016, DGE/SSA. Disponible en http://www.sinave.gob.mx/

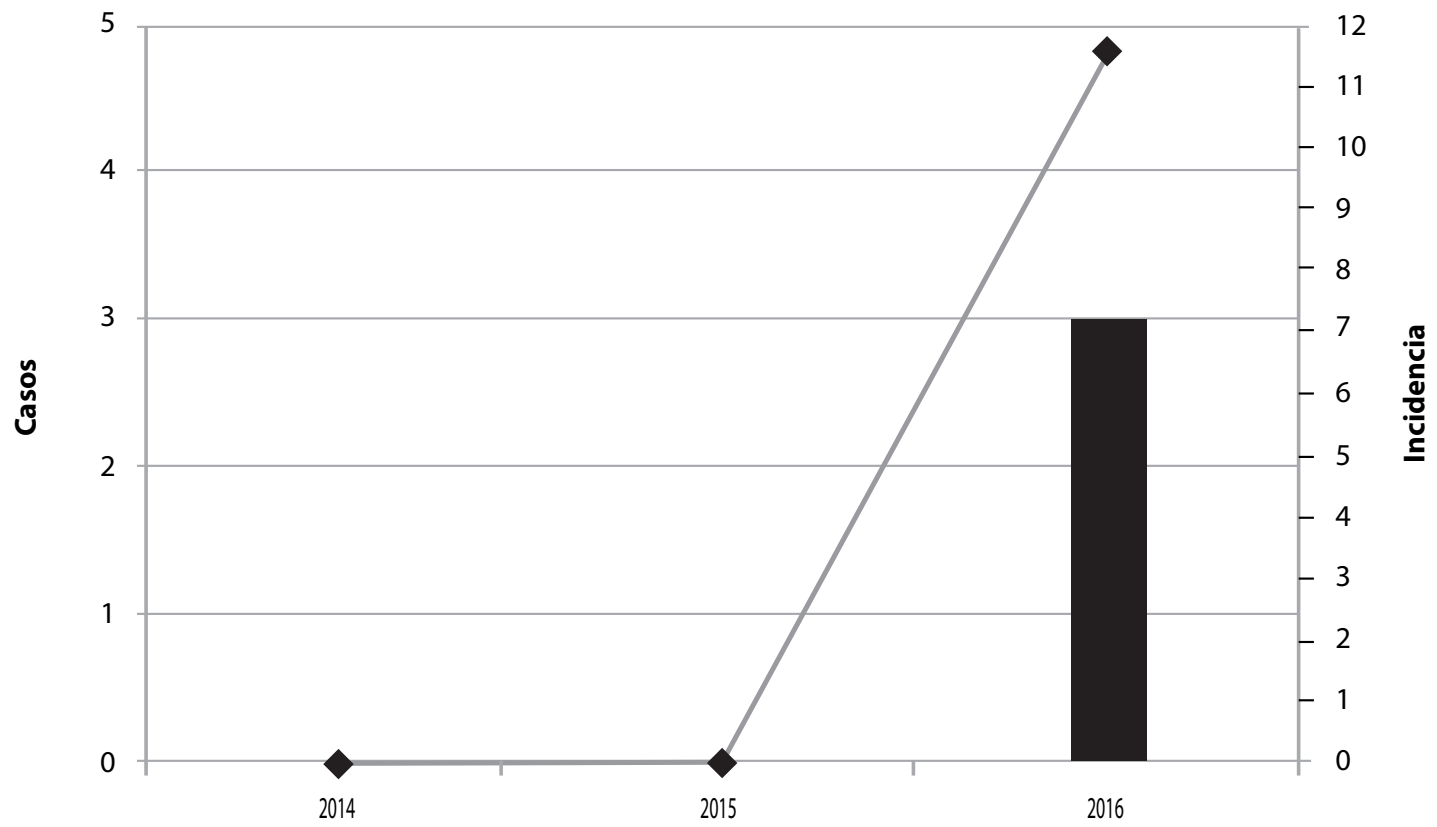

Figura 8. Casos e incidencia de síflis congénita según año Aguascalientes, 2014 -2016. Fuente: Anuario Estadístico 1990 - 2016, DGE/SSA. Disponible en http://www.sinave.gob.mx/

En el Hospital de la Mujer del Estado de Aguascalientes se presentaron, durante el año 2017, cuatro casos de sífilis primaria todos en pacientes menores de 24 años y dos casos de sífilis congénita.
El Instituto de Servicios de Salud del Estado de Aguascalientes (ISSEA) se encuentra en alerta para aplicar tamizaje con VDRL a toda mujer embarazada captada en primer nivel. Los casos positivos se es- 
tudian y se les realiza seguimiento epidemiológico como lo marca la Norma Oficial Mexicana 007 y 039.

Es evidente que la enfermedad presenta un aumento considerable en su incidencia, por lo que las pruebas de tamizaje en la población general deben ser consideradas. Las mujeres en edad reproductiva deben realizar tamizaje preconcepcional y en cuanto se capte una paciente embarazada, debe considerarse realizar la detección lo antes posible. Se debe educar en prevención primaria a la población, alertando sobre lo que sucede con las infecciones de transmisión sexual en los últimos años.

\section{Conclusiones}

Este caso clínico nos sirve para la reflexión sobre la importancia del tamizaje en toda paciente embarazada para que tanto la madre como el producto reciban los beneficios del tratamiento oportuno. Es importante que los médicos de primer contacto realicen su búsqueda en toda paciente embarazada en la consulta del control prenatal. Más importante aún en la educación para la prevención de todas las infecciones de transmisión sexual.

\section{Bibliografía}

1. Consejo de Salubridad General. Guía de Práctica Clínica Enfermedades de Transmisión sexual en el adolescente y adulto que produce úlceras genitales: herpes, sífilis, cancroide, linfogranuloma venéreo y granuloma inguinal. Disponible en: http://www.cenetec.salud.gob.mx/descargas/gpc/CatalogoMaestro/094_GPC_ETSadolescyadulto/enf_sexuales_evr_ cenetec $\overline{2}$.pdf

2. Sparling PF. Natural history of syphilis. In: SexuallyTransmitted Diseases, Holmes KK, Mardh PA, Sparling PF, et al (Eds), McGraw-Hill, New York 1990. p.213.

3. E. Leal, S. Campos, I. Pardo, M. Vázquez-Rodríguez, E. García-Jiménez y E. Moral. Sífilis y embarazo. Clin Invest Gin Obst. 2011;38(3):114-117. doi:10.1016/j.gine.2009.10.006

4. Álvarez-Hernández G, Salazar-Arriola SA, Bocanegra-Luna C. Guía para el diagnóstico y manejo de la sífilis en el embarazo, y prevención de la sífilis congénita. 1 ${ }^{a}$. Secretaría de Salud Pública del Estado de Sonora. 2012 Disponible en http://www.censida. salud.gob.mx/descargas/normatividad/guia_diagnostico_manejo_sifilis_congenita.pdf

5. Hawkes S, Matin N, Broutet N, Low N. Effectiveness of interventions to improve screening for syphilis in pregnancy: a systematic review and meta-analysis. Lancet Infect Dis 2011; 11:684.

6. Zhu L, Qin M, Du L, et al. Maternal and congenital syphilis in Shanghai, China, 2002 to 2006. Int J Infect Dis 2010; 14 Suppl 3:e45.

7. Newman L, Kamb M, Hawkes S, et al. Global estimates of syphilis in pregnancy and associated adverse outcomes: analysis of multinational antenatal surveillance data. PLoSMed 2013; 10:e1001396.

8. Rogozi?ska E, Kara-Newton L, Zamora JR, Khan KS. On-site test to detect syphilis in pregnancy: a systematic review of test accuracy studies. BJOG 2017; $124: 734$

9. Davey, Joseph; Prevalence of Curable Sexually Transmitted Infections in Pregnant Women in Low- and Middle-Income Countries From 2010 to 2015. Sex Transm Dis. 2016. 43(7): 450-458 doi:10.1097/ OLQ.0000000000000460

10. Cheng JQ, Zhou H, Hong FC, et al. Syphilisscreening and intervention in 500,000 pregnantwomen in Shenzhen, thePeople'sRepublic of China. Sex Transm Infect 2007; 83:347.

11. Lin, Jennifer S. MD; Eder, Michelle L. PhD; Bean, Sarah I. MPH. Screening for Syphilis Infection in Pregnant Women. Updated Evidence Report and Systematic Review. JAMA. US Preventive Services Task Force; 2018. 320(9):918-925. doi:10.1001/ jama.2018.7769

12. Qin JB, Feng TJ, Yang TB, et al. Synthesized prevention and control of one decade form other-to-child transmission of syphilis and determinants associated with congenital syphilis and adverse pregnancy outcomes in Shenzhen, South China. Eur J Clin Microbiol Infect Dis 2014; 33:2183.

13. Norma Oficial Mexicana NOM-007-SSA2-2016, Para la atención de la mujer durante el embarazo, parto y puerperio, y de la persona recién nacida.

14. Norma Oficial Mexicana NOM-039-SSA2-2014, Para la prevención y control de las infecciones de transmisión sexual 